\title{
Hcv coinfection, an important risk factor for hepatotoxicity in pregnant women starting antiretroviral therapy
}

\author{
Ingrid J.M. Snijdewind ${ }^{a, *}$, Colette Smit ${ }^{b}$, Mieke H. Godfried ${ }^{c}$, \\ Jeannine F.J.B. Nellen ${ }^{c}$, Frank de Wolf ${ }^{b, d}$, Kees Boer ${ }^{c}$, \\ Marchina E. van der Ende ${ }^{a}$
}

\footnotetext{
${ }^{a}$ Erasmus University Medical Centre, Postbus 2040, 3000 CA, Rotterdam, The Netherlands

b HIV Monitoring Foundation, Meibergdreef 9, 1105 AZ, Amsterdam, The Netherlands

' Academic Medical Centre, Postbus 22660, 1100 DD, Amsterdam, The Netherlands

'Imperial College, St Mary's Campus, 16 South Wharf Road, London, UK
}

Accepted 20 December 2011

Available online 23 December 2011

\section{KEYWORDS \\ HIV; \\ CART; \\ Nevirapine; \\ Pregnancy; \\ Side effects; \\ Hepatotoxicity; \\ Hepatitis $C$ virus}

\begin{abstract}
Summary Objectives: This retrospective cohort study evaluated the risk of hepatotoxicity in HIV-1 positive pregnant and non-pregnant women starting combined ART.

Methods: Data were used from the ATHENA observational cohort. The study population consisted of HIV-1 infected, therapy naïve, pregnant and non-pregnant women, followed between January 1997 and February 2008. Demographic, treatment and pregnancy related data were collected. Risk of hepatotoxicity was determined using univariate and multivariate logistic regression. Analyses were adjusted for age, region of origin, baseline HIV-RNA levels and CD4 cell counts, CART regimen and hepatitis B and C coinfection. ALT and AST values of more than 5 times ULN were considered as hepatotoxicity.

Results: Four-hundred and twenty-five pregnant and 1121 non-pregnant women were included. Independent risk factors of hepatotoxicity in all women were the presence of detectable HCV RNA (OR 5.48, 95\% Cl 2.25-13.38, $p<0.001$ ) and NVP use (OR 2.63, 95\% Cl 1.54-4.55, $p<0.001)$. Stratified for pregnancy, the adjusted risk of hepatotoxicity was significantly associated with HCV coinfection only during pregnancy (OR $23.53,95 \% \mathrm{CI}$ 4.69-118.01, $p<0.001)$. NVP use is related to hepatotoxicity in pregnant (OR $5.26,95 \% \mathrm{Cl}$ $1.61-16.67, p<0.005)$ as well as in non-pregnant women (OR 2.13, 95\% Cl 1.11-4.00, $p=0.02)$.
\end{abstract}

\footnotetext{
* Corresponding author. Erasmus MC, D418, Internal medicine, 's Gravendijkwal 230, 3015 CE Rotterdam, The Netherlands. Tel.: +31 107034529; fax: +31 104145525.

E-mail address: i.snijdewind@erasmusmc.nl (I.J.M. Snijdewind).
} 
Conclusion: HCV coinfection and NVP use are associated with a higher risk of CART induced hepatotoxicity in pregnant women.

(c) 2012 The British Infection Association. Published by Elsevier Ltd. All rights reserved.

\section{Introduction}

Antiretroviral therapy (ART) is used world-wide to prevent vertical transmission of HIV. In developing countries nevirapine (NVP) is the most frequently used drug to prevent vertical transmission. ${ }^{1}$ During the last decade studies from different regions in the world reported conflicting results on the risk on mainly NVP-related liver toxicity in pregnant women. ${ }^{1-10}$ One of the possible risk factors of hepatotoxicity is a CD4 $4^{+}$cell count $>250$ cells $/ \mu$ l. Most studies reported hepatotoxicity predominantly in women with $\mathrm{CD}^{+}$cell counts $>250 / \mathrm{mm}^{3} .^{2-3,5,8}$ A recent retrospective study from the UK found pregnancy to be significantly associated with hepatotoxicity, without an association with NVP use or $\mathrm{CD}^{+}$cell count. ${ }^{9}$

The HIV-1-positive ATHENA cohort in the Netherlands comprises a multi-ethnic group of women from different backgrounds with similar access to healthcare facilities. The aim of our study was to examine the effects of pregnancy, ethnicity, $\mathrm{CD}^{+}$cell count, hepatitis B (HBV) or $C(\mathrm{HCV})$ coinfection and combined ART (CART) on hepatotoxicity in women.

\section{Patients and methods}

\section{Study design and setting}

We conducted a retrospective cohort study among women enrolled in the AIDS Therapy and Evaluation in The Netherlands (ATHENA) ${ }^{11}$ cohort study between January 1997 and February 2008. Patients have provided written informed consent for their data to be anonymously recorded in a central database that is maintained by the HIV Monitoring Foundation. ${ }^{11}$ The study was reviewed and approved by the institutional review boards from all the involved institutions.

\section{Study population}

We included all cART naive women from this cohort in their reproductive phase of life (18-45 years), who started CART between January 1997 and February 2008. The women were first classified into two groups: pregnant or non-pregnant. The pregnant group comprised women who started cART for the first time, during pregnancy. We excluded pregnant women who started cART before being pregnant. The nonpregnant group included all women that started CART for the first time, and were never pregnant during the observational follow-up in the ATHENA cohort. CART was defined as a regimen with two nucleoside reverse transcriptase inhibitors (NRTIs) and either a third NRTI, a nonnucleoside reverse transcriptase inhibitor (NNRTI) or a protease inhibitor (PI). The duratrion of CART use was defined as start date first line of therapy until second line therapy, loss to follow-up date, date of death or date of closure of the dataset (February 2008). Women with high ALT or AST values, three times the upper limit of normal (30 IU) at start CART, were excluded from the study.

\section{Data collection}

Data were collected on demographics (age, region of origin), clinical and treatment characteristics, side effects, coinfection with HBV and HCV, Alanine-aminotransferase (ALT), Aspartate-aminotransferase (AST), baseline CD4 ${ }^{+} \mathrm{T}$ cell counts and baseline HIV-RNA levels. Baseline was defined as the start of CART. All women had routine check ups with ALT and AST levels being monitored in weeks 2, 4, 12 after start of CART and during a clinical visit every 3 months hereafter and just before the predicted date of birth. CART initiation date, duration and composition of the regimens were retrieved. The occurrence of hepatotoxicity is systemically collected and validated in the ATHENA database.

\section{Outcomes and study definitions}

The outcome of interest was the occurrence of hepatotoxicity in pregnant compared to non-pregnant women. The observational period for side effects was 40 weeks after start CART, as this is the mean duration of pregnancy. Hepatotoxicity was defined in accordance with the AIDS Clinical Trial Group criteria ${ }^{12}$ as grade 3 when ALT or AST values were 5-10 (150-300 IU) times the upper limit of normal (ULN), and as grade 4 when ALT or AST were $>10$ times ULN (>300 IU). Patients were considered to have chronic HBV infection when HBsAg could be detected and chronic HCV when HCV antibodies and HCV RNA were present at start CART.

\section{Statistical analyses}

Statistical analyses were performed using the SPSS statistical package PASW (version 17.0.2, IL, USA). Three different tests were used to compare Baseline characteristics at the start of CART initiation between non-pregnant and pregnant women. Mann-Whitney test was used to compare medians of age, $\mathrm{CD}^{+}$cell levels and HIV-RNA levels at start CART. Chi-square test was used to compare regions of origin, coinfections with HBV and HCV. In case of small numbers the Fisher's exact test was used to compare differences in outcome between non-pregnant and pregnant women. Using univariate and multivariate logistic regression analyses we evaluated risk factors for hepatotoxicity. Risk factors accounted for were age, cART regimen, region of origin, baseline HIV-RNA level, baseline $\mathrm{CD}^{+}{ }^{+} \mathrm{T}$-cell levels, coinfection with HBV and with HCV. Further analyses were stratified by regimen and pregnancy status. Variables with a $p$-value $<0.20$ in the univariate analyses were included in the multivariable logistic regression model. 


\section{Results}

Between 1997 and 2008, a total of 1924 HIV-1-positive treatment naive women initiated CART. Women were included from the first HIV positive test, and indexed at the time of first CART use. Of these women, 768 became pregnant at least once during follow-up. Only one pregnancy during CART use (the first) was included in the study. Of the women who became pregnant, 125 were already on CART before the start of pregnancy, 23 women started CART after delivery, and 135 women had an induced abortion or miscarriage in the first 16 weeks of the pregnancy. The remaining 485 pregnant women initiated CART during their pregnancy, 462 out of 485 women used CART for more than one week. Thirty-seven women used mono or dual therapy and were excluded. In total, 425 pregnant women, initiating CART with a minimal duration of 7 days, could be included in the study. Of the 1156 women who did not become pregnant during the observational period, 1121 started CART and continued using it for at least one week. Thirty-five women were excluded, due to less then 7 days usage of cART $(n=34)$ or monotherapy $(n=1)$. None of the pregnant women died during follow-up. In the non-pregnant group eight women died, three deaths were AIDS related, three deaths were non-AIDS related and in two cases the cause of death was unknown.

\section{Baseline characteristics}

Baseline demographic, laboratory and treatment characteristics are shown in Table 1. Pregnant women were younger ( 28 versus 33 years, $p$-value $<0.001)$, originated more often from Sub-Sahara Africa (SSA) (59\% versus $50 \%, p$-value $=0.006)$, had higher median $\mathrm{CD}^{+}$cell counts $(0.37$ versus $0.18, p$-value $<0.001)$ and lower HIVRNA levels ( $p$-value $<0.0001)$. Asian women were equally balanced among pregnant $(n=25 ; 5.2 \%)$ and nonpregnant $(n=77 ; 6.7 \%)$ women. Pregnant women were more often treated with a protease inhibitor (PI) based regimen (74.8\%) compared to non-pregnant women (42.0\%). In pregnant women 305/425 (71.8\%) started CART with a CD4 ${ }^{+}$cell count $>250 \mu$ l, as opposed to 303 / $1121(27.0 \%)$ in the non-pregnant women. The median duration of CART use in pregnancy was 15.9 weeks (IQR: 9.9-20.8). The median duration of the firstline CART regimen in non-pregnant women was 31.4 weeks (IQR: 9.6-85.4). The majority of women (>90\%) were infected heterosexually.

\section{Hepatotoxicity in women overall}

In all women a total of 77 cases $(5.0 \%)$ of grade 3 or 4 hepatotoxicity were reported (Table 1$)$. Independent risk factors of hepatotoxicity in all women were the presence of detectable HCV RNA (OR 5.48, 95\% Cl 2.25-13.38, $p<0.001)$ and NVP use (OR 2.63, 95\% Cl 1.54-4.55, $p<0.001$ ) (Table 2). The rate of hepatotoxicity was lower in pregnant $(n=16,3.8 \%)$ compared to non-pregnant ( $n=61,5.4 \%$ ) women. After adjustment for region of origin, hepatitis $B$ and $C$ coinfection, cART regimen, age at start CART, HIV-RNA level and $\mathrm{CD}^{+}$cell count at base line, the risk of hepatotoxicity did not differ between pregnant and non-pregnant women (OR $0.70,95 \% \mathrm{Cl} 0.38-1.28$, $p=0.25)$.

When analyses among all women were stratified by cART regimen, HCV coinfection remained an independent significant risk factor for hepatotoxicity in efavirenz and PI-using women only (OR 5.23, 95\% Cl 1.88-14.57, $p=0.002$ ) (data not shown).

\section{Hepatotoxicity in pregnant and non-pregnant women}

When the analysis was stratified by pregnancy, similar risk factors were identified (Table 3 ). In pregnant women detectable HCV-RNA and a NVP based regimen were both independently associated with a significantly higher risk of hepatotoxicity (OR 23.53, 95\% Cl 4.69-118.01, $p<0.001$ and OR 5.26, 95\% Cl 1.61-16.67, $p=0.005)$, while in nonpregnant women HCV coinfection was not found to be a significant risk factor. Separate analysis of CART in nonpregnant women demonstrated a moderate increased risk of hepatotoxicity for NVP compared to PI use (OR 2.13, 95\% Cl 1.11-4.00, $p=0.02$ ). The median time from cART initiation to grade 3 or 4 increase in ALT/AST levels was $7.56(0.57-39.29)$ weeks in non-pregnant and 4.57 $(0.14-17.00)$ weeks in pregnant woman, not a significant difference $(p=0.17)$.

We did a sensitivity analyses by excluding HCV coinfected women. In this analysis NNRTI use remained a significant risk factor for the occurrence of hepatotoxicity after treatment initiation.

Finally, NVP induced hepatotoxicity resulted in discontinuation of NVP in $89 \%(n=14)$ and $43 \%(n=26)$ in pregnant and non-pregnant women respectively.

\section{Discussion}

In this study we analysed the occurrence of hepatotoxicity after the start of CART in a group of HIV-1 infected pregnant and non-pregnant women. Overall we observed $5.0 \%$ hepatotoxicity within 40 weeks after the start of CART in all women. This rate did not differ between pregnant and non-pregnant women. The risk of hepatotoxicity in pregnant women was strongly associated with the presence of HCV-RNA. NVP was associated with an increased risk of hepatotoxicity in pregnant and nonpregnant women.

\section{Hepatotoxicity}

The occurrence of $5 \%$ hepatotoxicity is in agreement with proportions reported in several other studies ranging from 1.2 to $9 \% .^{1-4,6,8,9}$ Only one study, performed in Asian patients, reported a substantially higher rate of hepatotoxicity $(15.6 \%)$ in pregnant women using NVP. ${ }^{7}$ This study however had only a small proportion of patients tested for HBV or HCV, and the presence of a coinfection in this study may have added to the high percentage of hepatotoxicity, as HIV-positive Asian communities were found to have a high prevalence of HCV. ${ }^{13}$ 
Table 1 Demographic and clinical characteristics of pregnant and non-pregnant women initiating CART.

\begin{tabular}{|c|c|c|c|c|}
\hline & Total 1546 & $\begin{array}{l}\text { Non-pregnant women } \\
n=1121(\%)\end{array}$ & $\begin{array}{l}\text { Pregnant women, } \\
n=425\end{array}$ & $P$-value \\
\hline \multicolumn{5}{|l|}{ Age at start cART } \\
\hline Median (IQR) & $32(26.7-36.7)$ & $33(28.3-38.1)$ & $28(23.6-32.0)$ & $<0.0001$ \\
\hline \multicolumn{5}{|l|}{ Origin } \\
\hline NL, W Europe & $300(19.4)$ & $232(20.7)$ & $68(16)$ & \multirow[t]{3}{*}{0.006} \\
\hline SSA & $805(52.1)$ & $556(49.6)$ & $249(58.6)$ & \\
\hline Other & 441 (28.5) & $333(29.7)$ & $108(25.4)$ & \\
\hline \multicolumn{4}{|l|}{ CD4 at start } & \multirow[t]{3}{*}{$<0.0001$} \\
\hline Median (IQR) & $220(119-360)$ & $180(70-275)$ & $370(232-530)$ & \\
\hline Missing & 176 & 165 & 11 & \\
\hline \multicolumn{5}{|l|}{ RNA level at start } \\
\hline $\begin{array}{l}\text { Median } \\
\text { (Range) }\end{array}$ & $\begin{array}{l}3.7 \times 10 \log 4 \\
(17-2.1 \times 10 \log 8)\end{array}$ & $\begin{array}{l}7.8 \times 10 \log 4 \\
(17-2.1 \times 10 \log 8)\end{array}$ & $\begin{array}{l}6.4 \times 10 \log 3 \\
(25-7.5 \times 10 \log 5)\end{array}$ & \multirow[t]{2}{*}{$<0.0001$} \\
\hline Missing & 240 & 233 & 7 & \\
\hline \multicolumn{5}{|l|}{ HBV coinfection } \\
\hline Yes & $76(4.9)$ & $55(4.9)$ & $21(4.9)$ & \multirow[t]{3}{*}{0.25} \\
\hline No & $1355(87.6)$ & $975(87.0)$ & $380(89.4)$ & \\
\hline Missing & $115(7.4)$ & $91(8.1)$ & $24(5.6)$ & \\
\hline \multicolumn{5}{|l|}{ HCV coinfection } \\
\hline $\mathrm{AB}+$ & 1154 (74.6) & $814(72.6)$ & $340(80.0)$ & \multirow[t]{4}{*}{$<0.001$} \\
\hline $\mathrm{AB}+$ and $\mathrm{RNA}+$ & $34(2.2)$ & $23(2.1)$ & $11(2.6)$ & \\
\hline $\mathrm{AB}+$ and RNA- & $3(0.2)$ & $1(0.1)$ & $2(0.5)$ & \\
\hline Missing $A B$ or RNA & $355(23.0)$ & $283(25.2)$ & $72(16.9)$ & \\
\hline \multicolumn{5}{|l|}{ CART regime } \\
\hline NNRTI-based & $685(44.3)$ & $582(51.9)$ & $103(24.2)$ & \multirow[t]{11}{*}{$<0.0001$} \\
\hline Nevirapine & 359 & 257 & 102 & \\
\hline Efavirenz & 326 & 325 & 1 & \\
\hline PI-based & $789(51.0)$ & $471(42.0)$ & $318(74.8)$ & \\
\hline Nelfinavir & 403 & 136 & 267 & \\
\hline Lopinavir & 224 & 199 & 25 & \\
\hline Saquinavir/R & 58 & 39 & 19 & \\
\hline Indinavir & 34 & 29 & 5 & \\
\hline Others & 70 & 68 & 2 & \\
\hline Both & $27(1.7)$ & $23(2.1)$ & $4(0.9)$ & \\
\hline Triple NRTI only & $45(2.9)$ & $45(4.0)$ & & \\
\hline \multicolumn{5}{|l|}{ Hepatotoxicity } \\
\hline$N(\%)$ & $77(5.0)$ & $61(5.4)$ & $16(3.8)$ & 0.18 \\
\hline
\end{tabular}

Coinfection with HBV or HCV has been reported to be an independent risk factor for antiretroviral-associated hepatotoxicity, including NVP-related hepatotoxicity. ${ }^{14}$ First, there could be enhanced toxicity of pre-existing HCV- or HBV-coinfection. Secondly, cART may be associated with recovery of cell-mediated immunity, leading to immunemediated HBV- and HCV-specific liver cell damage and transaminase elevation. ${ }^{15}$ This is supported by a review of cohort studies, investigating the incidence of hepatotoxicity among patients receiving CART, that failed to identify a consistent association between a particular drug or drug class and the development of subsequent hepatotoxicity. ${ }^{14}$ Most studies among asymptomatic pregnant and nonpregnant women lack data on hepatitis coinfection. In The Netherlands, HBV and HCV serology is routinely assessed in HIV-positive patients, irrespective of liver enzymes or pregnancy. In our large cohort only $19.4 \%$ and $23.0 \%$ of women had missing data on coinfection, which enabled us to demonstrate the impact of a coinfection on CART or pregnancy-induced hepatotoxicity.

NVP is significantly associated with an increased risk of hepatotoxicity (OR 5.26, 95\% Cl 1.61-16.67, $p=0.005)$ in pregnant women and less evident in non-pregnant women (OR 2.13. 95\% Cl 1.11-4.00, $p=0.02$ ). This has been reported before ${ }^{3,8}$ and may be due to pregnancy related physiological effects: changing pharmacokinetics by altered activity of CYP2D6 and CYP3A4. ${ }^{16}$

Coinfection with HCV increases the risk of hepatotoxicity in pregnant women $(23.53(4.69-118.01 ; p<0.001)$. Pregnancy has been shown to be an independent risk 
Table 2 Risk factors for hepatotoxicity, analysis for all women.

\begin{tabular}{|c|c|c|c|c|c|}
\hline & $n$ & Univariate OR $(95 \% \mathrm{CI})$ & $P$-value & Multivariate OR $(95 \% \mathrm{CI})$ & $P$-value \\
\hline \multicolumn{6}{|l|}{ All women } \\
\hline Non pregnant & 1121 & 1 & & 1 & \\
\hline Pregnant & 425 & $0.68(0.39-1.19)$ & 0.18 & $0.70(0.38-1.28)$ & 0.25 \\
\hline \multicolumn{6}{|l|}{ Age quartiles } \\
\hline$<27$ & 406 & 1 & & & \\
\hline $27-32$ & 399 & $0.91(0.46-1.77)$ & 0.77 & & \\
\hline $32-37$ & 371 & $1.35(0.72-2.51)$ & 0.35 & & \\
\hline$>37$ & 370 & $1.04(0.54-2.02)$ & 0.90 & & \\
\hline \multicolumn{6}{|l|}{ Origin } \\
\hline NL, W Europe & 300 & 1 & & & \\
\hline SSA & 805 & $1.10(0.59-2.04)$ & 0.77 & & \\
\hline Other & 441 & $1.07(0.54-2.13)$ & 0.84 & & \\
\hline \multicolumn{6}{|l|}{ CD4 } \\
\hline$<200$ & 592 & 1 & & & \\
\hline $200-350$ & 414 & $0.78(0.42-1.42)$ & 0.41 & & \\
\hline $350-500$ & 184 & $1.04(0.50-2.16)$ & 0.92 & & \\
\hline$>500$ & 180 & $0.95(0.45-2.04)$ & 0.90 & & \\
\hline Missing & 176 & $1.09(0.52-2.27)$ & 0.82 & & \\
\hline \multicolumn{6}{|l|}{ HIV-RNA } \\
\hline Undetectable & 118 & 1 & & & \\
\hline Detectable & 1188 & $1.14(0.45-2.90)$ & 0.79 & & \\
\hline Missing & 240 & $1.51(0.53-4.25)$ & 0.44 & & \\
\hline \multicolumn{6}{|l|}{ HBV } \\
\hline Negative & 1355 & 1 & & & \\
\hline Positive & 76 & $1.31(0.51-3.36)$ & 0.57 & & \\
\hline Missing data & 115 & $0.50(0.16-1.61)$ & 0.25 & & \\
\hline \multicolumn{6}{|l|}{$\mathrm{HCV}$} \\
\hline$A B-$ & 1154 & 1 & & 1 & \\
\hline $\mathrm{AB}+, \mathrm{RNA}+$ & 34 & $4.81(2.01-11.50)$ & $<0.001$ & $5.48(2.25-13.38)$ & $<0.001$ \\
\hline $\mathrm{AB}+, \mathrm{RNA}-$ & 3 & NA & - & NA & - \\
\hline Missing & 355 & $0.59(0.31-1.14)$ & 0.12 & $0.59(0.311 .14)$ & 0.12 \\
\hline \multicolumn{6}{|l|}{ Medication } \\
\hline NVP & 359 & 1 & & 1 & \\
\hline EFV & 326 & $0.64(0.35-1.17)$ & 0.14 & $0.57(0.31-1.07)$ & 0.08 \\
\hline $\mathrm{PI}$ & 789 & $0.37(0.22-0.64)$ & 0.001 & $0.38(0.22-0.65)$ & $<0.001$ \\
\hline Both NNRTI/PI & 27 & $0.88(0.20-3.89)$ & 0.99 & $0.86(0.19-3.83)$ & 0.84 \\
\hline NO NNRTI/PI & 45 & $0.25(0.03-1.87)$ & 0.24 & $0.22(0.03-1.66)$ & 0.14 \\
\hline
\end{tabular}

factor for developing hepatotoxicity in other diseases. Pregnancy is also associated with immune suppression, and therefore may be responsible for susceptibility and poor outcome of infectious diseases. Pregnant women with hepatitis $E$ developed fulminant hepatic failure more frequently with mortality rates over $20 \%{ }^{17}$ This may add to the argument of testing for HCV in HIV pregnant women, especially when a NVP-based regimen is considered.

The strength of our study lies in the elaborate and detailed baseline demographic and clinical data recorded from a well-characterized population in the ATHENA cohort. Women from all social, ethnic and economic backgrounds have the same access to health care in the Netherlands. Therefore, selection bias was not likely to occur.

Nonetheless our data have several limitations. Our study is limited by its observational design. The data were recorded by individual hospital data collectors and were restricted to protocol. Furthermore, additional details on the clinical severity of hepatotoxicity were not obtainable. Occasionally data on $\mathrm{CD}^{+}$cell counts and liver enzymes were lacking. Data on alcohol consumption were not available. 
Table 3 Risk factors for hepatotoxicity, analysis for pregnant and non-pregnant women.

\begin{tabular}{|c|c|c|c|c|c|c|c|c|c|c|}
\hline & \multicolumn{5}{|c|}{ Pregnant women } & \multicolumn{5}{|c|}{ Non-pregnant women } \\
\hline & $n$ & Univariate OR $(95 \% \mathrm{Cl})$ & $P$-value & Multivariate OR $(95 \% \mathrm{Cl})$ & $P$-value & $n$ & Univariate OR $(95 \% \mathrm{Cl})$ & $P$-value & Multivariate OR $(95 \% \mathrm{CI})$ & $P$-value \\
\hline \multicolumn{11}{|l|}{ Age quartiles } \\
\hline$<27$ & 189 & 1 & & 1 & & 217 & 1 & & 1 & \\
\hline $27-32$ & 129 & $2.65(0.76-9.26)$ & 0.13 & $2.47(0.65-9.38)$ & 0.18 & 270 & $0.52(0.23-1.18)$ & 0.12 & $0.51(0.22-1.17)$ & 0.11 \\
\hline $32-37$ & 79 & $1.83(0.40-8.35)$ & 0.44 & $1.43(0.26-7.78)$ & 0.68 & 292 & $0.99(0.50-1.98)$ & 0.98 & $1.03(0.51-2.08)$ & 0.94 \\
\hline$>37$ & 28 & $3.56(0.62-20.40)$ & 0.15 & $4.72(0.59-37.82)$ & 0.14 & 342 & $0.66(0.32-1.37)$ & 0.26 & $0.63(0.30-1.32)$ & 0.22 \\
\hline \multicolumn{11}{|l|}{ Origin } \\
\hline NL, W Europe & 68 & 1 & & & & 232 & 1 & & & \\
\hline SSA & 249 & $0.91(0.24-3.39)$ & 0.88 & & & 556 & $1.19(0.59-2.40)$ & 0.64 & & \\
\hline Other & 108 & $0.62(0.12-3.16)$ & 0.56 & & & 333 & $1.22(0.57-2.61)$ & 0.62 & & \\
\hline \multicolumn{11}{|l|}{ CD4 } \\
\hline$<200$ & 73 & 1 & & & & 519 & 1 & & & \\
\hline $200-350$ & 113 & $0.42(0.07-2.58)$ & 0.35 & & & 301 & $0.92(0.48-1.75)$ & 0.80 & & \\
\hline $350-500$ & 102 & $1.46(0.35-6.03)$ & 0.60 & & & 82 & $0.90(0.31-2.63)$ & 0.85 & & \\
\hline$>500$ & 126 & $0.96(0.22-4.16)$ & 0.96 & & & 54 & $1.40(0.47-4.16)$ & 0.54 & & \\
\hline Missing & 11 & NA & - & & & 165 & $1.13(0.54-2.38)$ & 0.75 & & \\
\hline \multicolumn{11}{|l|}{ HIV-RNA } \\
\hline Detectable & 74 & 1 & & 1 & & 44 & 1 & & & \\
\hline Undetectable & 344 & $1.41(0.31-6.40)$ & 0.65 & $1.66(0.33-8.35)$ & 0.54 & 844 & $0.75(0.22-2.52)$ & 0.64 & & \\
\hline Missing & 7 & $6.00(0.47-76.14)$ & 0.17 & $5.98(0.34-103.94)$ & 0.22 & 233 & $0.87(0.24-3.18)$ & 0.84 & & \\
\hline \multicolumn{11}{|l|}{ HBV } \\
\hline $\mathrm{AB}+$ & 380 & 1 & & 1 & & 975 & 1 & & 1 & \\
\hline$A B-$ & 21 & $2.97(0.63-14.12)$ & 0.17 & $3.73(0.63-21.94)$ & 0.15 & 55 & $0.95(0.29-3.13)$ & 0.93 & $1.09(0.33-3.66)$ & 0.89 \\
\hline Missing data & 24 & $1.23(0.15-9.80)$ & 0.81 & $1.24(0.12-12.35)$ & 0.86 & 91 & $0.37(0.09-1.54)$ & 0.17 & $0.79(017-3.63)$ & 0.76 \\
\hline \multicolumn{11}{|l|}{$\mathrm{HCV}$} \\
\hline$A B-$ & 340 & 1 & & & & 814 & 1 & & 1 & \\
\hline $\mathrm{AB}+, \mathrm{RNA}+$ & 11 & $27.18(6.45-114.57)$ & $<0.001$ & $23.53(4.69-118.01)$ & $<0.001$ & 23 & $2.20(0.63-7.64)$ & 0.22 & $2.56(0.72-9.17)$ & 0.15 \\
\hline $\mathrm{AB}+, \mathrm{RNA}-$ & 2 & NA & - & - & - & 1 & NA & - & NA & \\
\hline $\mathrm{AB}$ missing & 72 & $3.55(1.09-11.52)$ & 0.035 & $3.09(0.82-11.72)$ & 0.10 & 283 & $0.32(0.14-0.75)$ & 0.009 & $0.34(0.14-.86)$ & 0.02 \\
\hline \multicolumn{11}{|l|}{ Medication } \\
\hline NVP & 102 & 1 & & 1 & & 257 & 1 & & 1 & \\
\hline EFV & 1 & NA & & NA & & 325 & $0.47(0.25-0.90)$ & 0.02 & $0.47(0.25-0.90)$ & 0.02 \\
\hline $\mathrm{PI}$ & 318 & $0.23(0.08-0.64)$ & 0.005 & $0.19(0.06-0.62)$ & 0.005 & 471 & $1.07(0.24-4.88)$ & 0.93 & $1.09(0.23-5.06)$ & 0.91 \\
\hline Both NNRTI/PI & 4 & NA & & NA & & 23 & $0.26(0.03-1.95)$ & 0.19 & $0.27(0.04-2.09)$ & 0.21 \\
\hline NO NNRTI/PI & & & & & & 45 & $0.66(0.34-1.27)$ & 0.21 & $0.63(0.33-1.22)$ & 0.17 \\
\hline
\end{tabular}




\section{Conclusion}

$\mathrm{HCV}$ coinfection is strongly associated with hepatotoxicity in pregnant HIV-infected women starting CART. NVP use increased the risk of hepatotoxicity in pregnant as well as in non-pregnant women. Hepatotoxicity was independent of $\mathrm{CD}^{+}$cell count, region of origin, detectable HIV-RNA levels and age.

\section{Contributors}

Ingrid J.M. Snijdewind: substantial contribution to conception and design of the study, analysis and interpretation of data, drafting the paper, final approval of the version to be published.

Colette Smit: substantial contributions to conception and design of the study, analysis and interpretation of data, revising it critically for important intellectual content, final approval of the version to be published.

Mieke H. Godfried: acquisition of data, revising it critically for important intellectual content, final approval of the version to be published.

Jeannine F.J.B. Nellen: acquisition of data, revising it critically for important intellectual content, final approval of the version to be published.

Frank de Wolf: acquisition of data, revising it critically for important intellectual content, final approval of the version to be published.

Kees Boer: acquisition of data, revising it critically for important intellectual content, final approval of the version to be published.

Marchina E. van der Ende: substantial contribution to conception and design, acquisition of data, analysis and interpretation of data, final approval of the version to be published.

\section{Conflict of interest}

The authors have no conflicting interests.

\section{Collaborators}

The ATHENA database is supported by a grant from the Dutch Health Minister and was set up and is maintained by the HIV Monitoring Foundation. The physicians and data analysts include ( ${ }^{*}$ site coordinating physicians) the following individuals: F. de Wolf (Director), D.O. Bezemer, L.A.J. Gras, A.M. Kesselring, A.I. van Sighem, C. Smit, and S. Zhang (Data Analysis Group), and S. Zaheri (Data Collection), HIV Monitoring Foundation, Amsterdam; W. Bronsveld* and M.E. Hillebrand-Haverkort, Medical Center Alkmaar, Alkmaar; J.M. Prins*, J. Branger, J.K.M. Eeftinck Schattenkerk, J. Gisolf, M.H. Godfried, J.M.A. Lange, K.D. Lettinga, J.T.M. van der Meer, F.J.B. Nellen, T. van der Poll, P. Reiss, Th.A. Ruys, R. Steingrover, G. van Twillert, J.N. Vermeulen, S.M.E. Vrouenraets, M. van Vugt, and F.W.M.N. Wit, K. Boer, Academic Medical Center of the University of Amsterdam, Amsterdam; T.W. Kuijpers, D. Pajkrt, and H.J. Scherpbier, Emma Children's Hospital, Amsterdam; A. van Eeden, Medical Center Jan van Goyen, Amsterdam; K.
Brinkman*, G.E.L. van den Berk, W.L. Blok, P.H.J. Frissen, J.C. Roos, W.E.M. Schouten, and H.M. Weigel, Onze Lieve Vrouwe Gasthuis, Amsterdam; J.W. Mulder*, E.C.M. van Gorp, and J. Wagenaar, Slotervaart Hospital, Amsterdam; J. Veenstra*, St. Lucas Andreas Hospital, Amsterdam; S.A. Danner*, M.A. van Agtmael, F.A.P. Claessen, R.M. Perenboom, A. Rijkeboer, and M.G.A. van Vonderen, Free University Medical Center, Amsterdam; C. Richter* and J. van der Berg, Hospital Rijnstate, Arnhem; R. Vriesendorp* and F.J.F. Jeurissen, Medical Center Haaglanden, location Westeinde, Den Haag; R.H. Kauffmann* and K. Pogány, Haga Hospital, location Leyenburg, Den Haag; B. Bravenboer *, Catharina Hospital, Eindhoven; C.H.H. ten Napel * and G.J. Kootstra, Medisch Spectrum Twente, Enschede; H.G. Sprenger*, S. van Assen, and J.T.M. van Leeuwen, University Medical Center Groningen, Groningen; R. Doedens and E.H. Scholvinck, University Medical Center Beatrix kliniek, Groningen; R.W. ten Kate * and R. Soetekouw, Kennemer Gasthuis, Haarlem; D. van Houte* and M.B. Polée, Medical Center Leeuwarden, Leeuwarden; F.P. Kroon*, P.J. van den Broek, J.T. van Dissel, and E.F. Schippers, Leiden University Medical Center, Leiden; G. Schreij*, S. van der Geest, S. Lowe, and A. Verbon, Academic Hospital Maastricht, Maastricht; P.P. Koopmans*, R. van Crevel, R. de Groot, M. Keuter, F. Post, A.J.A.M. van der Ven, and A. Warris, Radboud University Nijmegen Medical Center, Nijmegen; M.E. van der Ende*, I.C. Gyssens, M. van der Feltz, J.L. Nouwen, B.J.A. Rijnders, and T.E.M.S. de Vries, Erasmus Medical Center, Rotterdam; G. Driessen, M. van der Flier, and N.G. Hartwig, Erasmus Medical Center Sophia, Rotterdam; J.R. Juttman*, M.E.E. van Kasteren, and C. van de Heul, St. Elisabeth Hospital, Tilburg; I.M. Hoepelman*, M.M.E. Schneider, M.J.M. Bonten, J.C.C. Borleffs, P.M. Ellerbroek, C.A.J.J. Jaspers, T. Mudrikove, C.A.M. Schurink, and E.H. Gisolf, University Medical Center Utrecht, Utrecht; S.P.M. Geelen, T.F.W. Wolfs, and T. Faber, Wilhelmina Children's Hospital, Utrecht; A.A. Tanis*, Hospital Walcheren, Vlissingen; P.H.P. Groeneveld*, Isala Clinics, Zwolle; J.G. den Hollander*, Medical Center Rijnmond-Zuid, location Clara, Rotterdam; A.J. Duits and K. Winkel, St. Elisabeth Hospitaal/Stichting Rode Kruis Bloedbank, Willemstad, Curaçao.

\section{Acknowledgements}

The authors would like to thank all hospitals for their collaboration in the ATHENA observational cohort study. The authors would like to thank the HIV Monitoring Foundation for allowing the use of the data and their support and Professor J.H.P. Wilson for reviewing the manuscript.

\section{References}

1. Black V, Hoffman RM, Sugar CA, Menon P, Venter F, Currier JS, et al. Safety and efficacy of initiating highly active antiretroviral therapy in an integrated antenatal and HIV clinic in Johannesburg, South Africa. J Acquir Immune Defic Syndr 2008 Nov 1; 49(3):276-81

2. Kondo W, Carraro EA, Prandel E, Dias JM, Perini J, Macedo RL, et al. Nevirapine-induced side effects in pregnant women: 
experience of a Brazilian university hospital. Braz J Infect Dis 2007 Dec;11(6):544-8.

3. Lyons F, Hopkins S, Kelleher B, McGeary A, Sheehan G, Geoghegan J, et al. Maternal hepatotoxicity with nevirapine as part of combination antiretroviral therapy in pregnancy. HIV Med 2006 May;7(4):255-60.

4. Joao EC, Calvet GA, Menezes JA, D'Ippolito MM, Cruz ML, Salgado LA, et al. Nevirapine toxicity in a cohort of HIV-1infected pregnant women. Am J Obstet Gynecol 2006 Jan; 194(1):199-202.

5. Marazzi MC, Germano P, Liotta G, Guidotti G, Loureiro S, da Cruz Gomes A, et al. Safety of nevirapine-containing antiretroviral triple therapy regimens to prevent vertical transmission in an African cohort of HIV-1-infected pregnant women. HIV Med $2006 \mathrm{Jul} ; 7(5): 338-44$.

6. Natarajan U, Pym A, McDonald C, Velisetty P, Edwards SG, Hay $P$, et al. Safety of nevirapine in pregnancy. HIV Med 2007 Jan;8(1):64-9.

7. Phanuphak N, Apornpong T, Teeratakulpisarn S, Chaithongwongwatthana S, Taweepolcharoen C, Mangclaviraj $\mathrm{S}$, et al. Nevirapine-associated toxicity in HIVinfected Thai men and women, including pregnant women. HIV Med 2007 Sep;8(6):357-66.

8. Jamisse L, Balkus J, Hitti J, Gloyd S, Manuel R, Osman N, et al. Antiretroviral-associated toxicity among HIV-1-seropositive pregnant women in Mozambique receiving nevirapine-based regimens. J Acquir Immune Defic Syndr 2007 Apr 1;44(4): 371-6.

9. Ouyang DW, Shapiro DE, Lu M, Brogly SB, French AL, Leighty RM, et al. Increased risk of hepatotoxicity in HIV- infected pregnant women receiving antiretroviral therapy independent of nevirapine exposure. AIDS 2009 Nov 27;23(18): 2425-30.

10. Coffie PA, Tonwe-Gold B, Tanon AK, Amani-Bosse C, Bedikou G, Abrams EJ, et al. Incidence and risk factors of severe adverse events with nevirapine-based antiretroviral therapy in HIVinfected women. MTCT-Plus program, Abidjan, Cote d'Ivoire. BMC Infect Dis 2010;10:188.

11. van Sighem Al, van de Wiel MA, Ghani AC, Jambroes $M$, Reiss $P$, Gyssens IC, et al. Mortality and progression to AIDS after starting highly active antiretroviral therapy. AIDS 2003 Oct 17; 17(15):2227-36.

12. Group. Act, Table of grading severity of adult adverse experiences. Rockville, MD: Division of AIDS, National Institute of Allergy and Infectious Disease; 1996.

13. Brewer DD, Khan AA. HCV and HIV prevalences strongly correlated in Asian communities with reservoirs of HIV in high-risk groups. J Infect Dev Ctries 2010 Jul;4(7):442-7.

14. Becker S. Liver toxicity in epidemiological cohorts. Clin Infect Dis 2004 Mar 1;38(Suppl. 2):S49-55.

15. Sepkowitz KA. Effect of HAART on natural history of AIDSrelated opportunistic disorders. Lancet 1998 Jan 24; 351(9098):228-30.

16. Tracy TS, Venkataramanan R, Glover DD, Caritis SNNational Institute for Child H, Human Development Network of MaternalFetal-Medicine U. Temporal changes in drug metabolism (CYP1A2, CYP2D6 and CYP3A activity) during pregnancy. Am J Obstet Gynecol 2005 Feb;192(2):633-9.

17. Krawczynski K, Aggarwal R, Kamili S, Hepatitis E. Infect Dis Clin North Am. 2000 Sep;14(3):669-87. 